*Doutoranda em Direito pela Universidade Federal do Paraná E-mail: juliana.pavao@hotmail. com

**Doutora em Direito pela Universidade Federal do Paraná Docente do Programa de Mestrado e Doutorado em Direito Negocial e da Graduação da Universidade Estadual de Londrina

E-mail: rita.tarifa@gmail.com

\section{A PROTEÇÃO DE DADOS CLÍNICOS DURANTE A PANDEMIA DA COVID-19: COMENTÁRIOS À LUZ DOS DIREITOS DA PERSONALIDADE E DOS REFERENCIAIS BIOÉTICOS}

\author{
THE PROTECTION OF CLINICAL DATA DURING \\ THE COVID-19 PANDEMIC: COMMENTS IN \\ THE LIGHT OF PERSONALITY RIGHTS AND \\ BIOETHICAL REFERENCES
}

\section{Juliana Carvalho Pavão* Rita de Cássia Resquetti Tarifa Espolador**}

Como citar: PAVÃO, Juliana Carvalho; ESPOLADOR, Rita de Cássia Resquetti Tarifa. A proteção de dados clínicos durante a pandemia da covid-19: comentários à luz dos direitos da personalidade e dos referenciais bioéticos. Scientia luris, Londrina, v. 25, n. 3, p. 125-140, nov. 2021. DOI: 10.5433/21788189.2021v25n3p125. ISSN: 2178-8189.

Resumo: A sociedade durante o ano de 2020 tem sofrido muito com a pandemia de Covid-19, resultando em reflexos em diversas áreas como o campo o jurídico. O presente trabalho tem por objetivo analisar o tratamento de dados clínicos, no contexto brasileiro, durante o período da pandemia de Covid-19. A análise tem como base a teoria geral dos direitos da personalidade e os referenciais bioéticos, com o intuito de demonstrar que tais campos são fundamentais para nortear as escolhas nesse período excepcional que o país enfrenta. Diante disso, a pesquisa utiliza o método dedutivo, realizando um estudo bibliográfico e legislativo. Conclui-se que os direitos a pessoa, principalmente a privacidade, devem ser preservados nesse período, e devese utilizar a teoria geral dos direitos da personalidade e os referenciais bioéticos como balizar ponderadoras das questões que surgem envolvendo dados clínicos.

Palavras-chave: Bioética, Covid-19. Dados clínicos. Direitos da Personalidade. Privacidade.

Abstract: Society during the year 2020 has suffered greatly from the Covid-19 pandemic, resulting in reflections in various areas such as the legal field. This paper aims to analyze the treatment of clinical data, in the Brazilian context, during the period of the Covid-19 pandemic. The analysis is based on the general 
theory of personality rights and on bioethical references, in order to demonstrate that these fields are fundamental for guiding choices in this exceptional period that the country is facing. Therefore, this research uses the deductive method, conducting a bibliographic and legislative study. It concludes that the rights of the individual, especially privacy, should be preserved in this period, and the general theory of personality rights and bioethical references should be used as a pondering guide for questions that involve clinical data.

Keywords: Bioethics. Covid-19. clinical data. Personality rights. Privacy. 


\section{INTRODUÇÃO}

A humanidade tem enfrentado uma terrível pandemia, decorrente do novo coronavírus. Devido a situação emergencial declarada por diversos países, algumas medidas tiveram que ser adotadas, muitas afetando diretamente os direitos fundamentais garantidos no texto constitucional.

Nesse aspecto, o presente texto analisa o tratamento sobre os dados pessoais, mais especificamente os dados clínicos, durante este momento. Muitas pessoas estão ingressando nos hospitais, realizando diversos exames, outras estão sendo voluntárias para a realização de testes com o objetivo de encontrar uma cura para a doença. Todavia, nesse cenário, questiona-se: qual a proteção aos dados clínicos? Como tratar dos dados clínicos em uma situação tão excepcional que envolve um nítido conflito entre privacidade e saúde?

O presente trabalho busca analisar o questionamento citado sob os prismas da teoria geral dos direitos da personalidade e dos referenciais bioéticos, tentando solucionar a questão levantada. Além disso, a pesquisa se desenvolve com base no método dedutivo, realizando uma análise bibliográfica e legislativa, com destaque as medidas que foram ou tentar ser implantadas no território nacional afetas aos dados pessoais.

Após essa breve introdução, deve-se iniciar o estudo por meio da contextualização da pandemia de COVID-19 e a compreensão de como a mesma está afetando o tratamento dos dados pessoais.

\section{PANDEMIA DE COVID-19 E O TRATAMENTO DE DADOS CLÍNICOS}

O ano de 2020 está sendo marcado pela pandemia de COVID-19. Após notificação da China, em 31 de dezembro de 2019, sobre vários casos de pneumonia desconhecida, diversos países começaram, um curto espaço de tempo, notificar casos semelhantes. (ORGANIZAÇÃO MUNDIAL DA SAÚDE, 2020).

A OMS declarou que a doença é causada pelo novo coronavírus denominado de COVID-19. Devido a grande transmissão do vírus e o crescimento de casos confirmados no mundo, a OMS, em 11 de março de 2020, declarou que o mundo estava enfrentando uma pandemia.

$\mathrm{O}$ grande problema presente nessa pandemia refere-se a rápida transmissão do vírus. $\mathrm{O}$ aumento do número de infectados acabou ocasionado a lotação dos hospitais, e consequentemente a falta de profissionais de saúde e equipamentos de proteção (HARVEY, 2020).

Governos começaram a perceber que seus sistemas de saúde eram falhos e não conseguiriam atender a alta demanda que surgia (HARVEY, 2020), isto é resultado de políticas adotadas no passado que não priorizavam o sistema de saúde coletiva ${ }^{1}$.

Contudo, para enfrentar a pandemia, faz-se necessária a adoção de medidas rápidas e

1 A título de exemplo, nos Estados Unidos da América, o governo não estava financiando a saúde pública devido a priorização da política de austeridade destinada a financiar redução de impostos e subsídios as grandes empresas e aos ricos. (HARVEY, 2020). 
urgentes. Mas as respostas devem sempre questionar "que tipo de mundo habitaremos quando a tempestade passar" (HARARI, 2020), porque as atitudes adotadas podem ter reflexos estendidos para o futuro, principalmente no campo dos Direitos Fundamentais e da Personalidade.

Uma das medidas adotadas é a vigilância total da população. Um dos países que adota essa medida é a China, vigiando a população por meio dos celulares e de câmeras nas ruas, além disso, o governo obriga os cidadãos a verificar e relatar sua temperatura e condições médicas (HARARI, 2020). Em Israel, o governo autorizou a utilização de tecnologias de vigilância de terroristas para rastrear os pacientes com coronavírus (HARARI, 2020).

Tais medidas mostram que os governos estão priorizando a saúde dos seus cidadãos em detrimento das suas privacidades. Todavia, tal escolha é falsa, porque outros países que não adotam tais medidas, tem conseguido combater o vírus, sem violar a privacidade dos cidadãos (HARARI, 2020).

Ademais, tais medidas ensejam dois problemas principais. O primeiro é que a população não saberá como seus dados, que são dados sensíveis, serão utilizados pelos governos, e segundo, se tais medidas serão realmente temporárias. Na segunda questão o receito reside no fato que alguns países decidirem permanecer com a vigilância, mesmo após o fim da pandemia, sob o argumento que outras doenças podem surgir (HARARI, 2020).

Então, fica evidente o conflito entre os dados sensíveis no campo médico e o direito da privacidade do cidadão durante o enfrentamento da pandemia. Como analisar essa questão em uma situação tão excepcional enfrentada pelo mundo?

Deve-se, primeiro, evidenciar que o direito da privacidade é um Direito Fundamental e Direito Humano garantido em diversos documentos internacionais. Segundo, apesar da atual situação excepcional e urgente, medidas sem reflexão e estudo não podem ser tomadas prejudicando direitos fundamentais, o que é destacado por órgãos internacionais através de recomendações.

Percebe-se que o momento atual não pode ser uma justificativa para políticas autoritárias e violadoras dos Direitos Fundamentais, devendo basear as decisões nos direitos já previstos e até nos referenciais bioéticos, como será demonstrado nos próximos tópicos.

No território nacional, preocupados com os aspectos bioéticos referentes a privacidade dos pacientes, antes da pandemia, um Comitê da Pontifícia Universidade Católica do Rio Grande do Sul publicou a "Recomendações para a proteção da privacidade do paciente". Segundo eles, "A privacidade da informação médica é hoje tão importante que a obtenção de consentimento informado sobre armazenamento de dados clínicos faz parte do processo de praticamente todas as cirurgias e internações clínicas de instituições hospitalares.”(CARVALHAL, 2017).

Tendo em vista essa proteção aos dados pessoais, assunto tratado a seguir, as informações médicas do paciente devem ser preservadas. Para essa preservação, o texto apresenta recomendações, dentre elas: "difundir entre futuros profissionais da área da saúde e da informática conceitos que valorizem a privacidade e a confidencialidade dos dados médicos" e "lembrar que cabe ao paciente decidir quais de seus dados poderão ser disponibilizados, para quem e sob quais circunstâncias"(CARVALHAL, 2017). 
Ingressando no campo legislativo brasileiro, existe a Lei Geral de Proteção de Dados (Lei n.13.709/2018 - LGPD), tratando da proteção dos dados antes mesmo da pandemia (BRASIL, 2018). A necessidade de uma lei decorreu do aumento da utilização das tecnológicas e dos dados, característicos de uma sociedade da informação (SARLET; KEINERT, 2015). Resultando na preocupação com a proteção dos dados pessoas, o que é uma questão primordial nas sociedades contemporâneas, porque a informação é muitas vezes utilizada como ferramenta política e/ou econômica (GEDIEL; CORRÊA, 2008).

Reformula-las, assim, a doutrina dos direitos da personalidade, principalmente no tocante a privacidade, possibilitaria ao individuo controlar o acesso e uso dos dados referentes a sua identidade. Mas, sem olvidar que a tutela dos dados pessoais sofre pressões. Primeiramente pelo Estado para aumentar a quantidade de informações sobre os cidadãos, e depois, pelo mercado, no tocante aos consumidores (GEDIEL; CORRÊA, 2008, p. 145).

Justamente sobre essa primeira pressão e que se nota a divulgação de dados pessoais no atual período de pandemia. Todavia, antes de adentrar nessa questão, deve-se, primeiro, retornar a análise do contexto brasileiro pré-pandemia. No contexto nacional, além da LGPD, houve a aprovação da Proposta de Emenda Constitucional n ${ }^{\circ}$ 17/2019, incluindo o direito à proteção de dados pessoais na lista das garantias individuais.

A LGPD trata do dado pessoal e do dado pessoal sensível. O primeiro é a "informação relacionada a pessoa natural identificada ou identificável" (Art. $5^{\circ}$, I da LGPD), enquanto que o dado pessoal sensível é o "dado pessoal sobre origem racial ou étnica, convicção religiosa, opinião política, filiação a sindicato ou a organização de caráter religioso, filosófico ou político, dado referente à saúde ou à vida sexual, dado genético ou biométrico, quando vinculado a pessoa natural" (Art. 5\%, II, LGPD).

O tratamento de dados pessoais sensíveis apenas poderá ocorrer em situações excepcionais previstas na Lei, quando for consentido pelo titular ou representante para finalidade específica (Art. 11, I, LGPD) ou, sem o consentimento do titular, quando for indispensável (Art. 11, II, LGPD). Dentre as situações indispensáveis, a Lei cita, dentre várias hipóteses, a "realização de estudos por órgão de pesquisa, garantida, sempre que possível, a anonimização dos dados sensíveis" (Art. 11, II, c, LGPD) e a "tutela da saúde, exclusivamente, em procedimento realizado por profissionais de saúde, serviços de saúde ou autoridades sanitárias” (Art. 11, II, f, LGPD).

Por meio dessas hipóteses excepcionais, pode-se utilizar dados clínicos para enfrentar a pandemia. Ademais, governos tem utilizados técnicas de rastreio da população para monitoramento, tentando reduzir a proliferação do vírus.

Observando casos concretos, deve-se citar a Medida Provisória n ${ }^{\circ} 954$ em 17 de abril de 2020, que determinava que as prestadoras de serviço de telecomunicações deveriam compartilhar com o Governo Federal suas bases de dados sobre seus usuários. O Governo argumentou que necessitava dos dados para pesquisa do IBGE. Tal medida foi questionada judicial e a ADIN n ${ }^{\circ} 6387 /$ DF, em 9 de abril de 2020, que determinou, de forma liminar, a suspensão dos efeitos da medida provisória (CORREAA; LUZ, 2020). 
Em âmbito estadual, deve-se recorda que no Estado de São Paulo foi criado o programa SIMI (Sistema de Monitoramento Inteligente) em 9 de abril de 2020, com o intuito do governo estadual obter dados para medir o distanciamento social no estado, e enviar alertas para áreas com mais casos de contágio. Para isso ser possível, foi firmada uma parceria do governo com as operadoras de telefonia Vivo, Claro, Oi e TIM para utilização dos seus dados georeferenciais dos seus usuários.

Contudo, tal sistema gerou questionamentos acerca da violação da intimidade e privacidade dos cidadãos. Diante disso, houve a formulação de uma demanda judicial perante o TJ-SP. Em primeiro grau, foi determinada a suspensão do sistema, contudo, em grau de recurso, a decisão foi reformada, pelo entendimento de que não teria havido violação da privacidade. Em outro recurso, naquele momento ao Superior Tribunal de Justiça, a sentença do Tribunal foi mantida, continuando ativo o sistema no Estado.

O tratamento dos dados pessoais tem sido utilizado pelos governos como fundamento para enfrentar a pandemia de COVID-19. Contudo, deve-se recordar da crítica apresentada por Harari, que tal aplicação conduz a uma violação de Direitos Fundamentais e questionar se a situação retornará à normalidade após o término da pandemia. Nesse contexto, Luciana Dadalto (2020) levanta a necessidade de estudar e traçar limites éticos e jurídicos a respeito do tratamento e proteção de dados nesse período de contágio.

Contudo, a questão torna-se mais complexa quando envolve dados clínicos. Segundo a LGPD tais dados são considerados dados sensíveis, mas em determinadas hipóteses podem ser utilizados, como previsto no art. 11 da Lei.

$\mathrm{Na}$ atual realidade, existem duas situações distintas relacionadas aos dados clínicos, a primeira é sobre a divulgação de dados clínicos relacionados a exames de COVID-19 e a segunda é sobre pesquisas clínicas para o tratamento da doença.

No primeiro caso, houve um caso judicial muito divulgado no país sobre o pedido para o presidente da República Jair Messias Bolsonaro divulgar seus exames médicos sobre a COVID-19. O presidente da república foi testado duas vezes e informou para a imprensa que não estava contaminado com o novo coronavírus, mas não apresentou seus exames (TAVARES, 2020). Legalmente, o presidente não detém obrigação de mostrar seus exames, porque se tratam de dados pessoais sensíveis protegidos pela LGPD.

Entretanto, o jornal O Estado de S. Paulo ingressou na Justiça Federal em São Paulo requerendo que o presidente entregasse os laudos médicos. A justificativa do pedido se baseava na existência de vários casos confirmados de COVID-19 de membros do governo próximos ao presidente e a conduta desrespeitosa da autoridade com relação aos protocolos de distanciamento social e isolamento (TAVARES, 2020).

Após diversos trâmites legais, no qual a decisão foi deferida, reformada e outros procedimentos, o ministro Ricardo Lewandowski decidiu a favor da entrega dos exames. Então, o governo entregou os dois exames nos quais conta que o presidente não estava infectado com o vírus (TAVARES, 2020). 
Apesar da discussão judicial entre o jornal e o presidente não ter se encerrado, pode-se observar pontos importantes. Primeiramente, por decisão judicial, foi ponderado o direito à privacidade em contraponto ao interesse público, prevalecendo o segundo e determinando que dados sensíveis fossem divulgados. Segundo, trata-se de uma situação excepcional no campo da saúde e, especificamente envolvendo uma autoridade política com atitudes capazes gerar riscos a toda a sociedade, se estivesse infectado. Então, a violação da privacidade foi considerada justificada.

Outro caso mais recente sobre divulgação de dados relacionados a COVID-19 ocorreu em Arapongas (PR), com a exposição, de forma ilegal, dos nomes de pacientes com esta doença. Uma lista com nomes, telefones e endereços foi divulgada, violando claramente o direito dos pacientes a privacidade. (JACOMINI, 2020).

Outra situação, refere-se as pesquisas e estudos clínicos sobre o novo vírus. Vários documentos, tanto de órgãos internacionais como de Estados, tem apresentados recomendações de como tratar dessa questão sem violar direitos dos pacientes ou voluntários.

No âmbito da União Europeia, foi emitido o "Guidance on the management of clinical trials during the covid-19 pandemic" que apresenta, entre vários pontos, a exigência do consentimento informado dos participantes de ensaios clínicos (EUROPEAN MEDICINES AGENCY, 2020).

No Estado Italiano, o documento "Answer to the requested urgente opinion on ethical issues regarding to the use of invasie assisted ventilation in patients all age with serious desabilities in raltion to Covid-19 pandemic" elaborado pelo Comitê de Bioética da República de São Marino, (2020, p.1-5), afirma que, mesmo durante a pandemia, a avaliação bioética deve ser realizada, respeitando à dignidade da pessoa e aos direitos humanos.

A Comissão Interamericana de Direitos Humanos por meio da Resolução1/2020 trata, como um dos pontos, da necessidade de proteção dos dados pessoais. A Recomendação n. 12 afirma a necessidade de consentimento prévio e informado das pessoas sob o tratamento da doença e a preservação dos seus dados pessoais (COMISSÃO INTERAMERICANA DE DIREITOS HUMANOS, 2020).

A Recomendação n. 35 trata da proteção do direito à privacidade e dos dados pessoais sensíveis. Nesse disposto está expresso, além da proteção ao direito, a necessidade de obtenção do consentimento das pessoas sobre o recolhimento e compartilhamento dos dados sensíveis. Destaca que nesse período de emergência, os dados devem ser recolhido com a finalidade de combater a pandemia, sem permissão de compartilhamento com fim comercial ou de outra natureza (COMISSÃO INTERAMERICANA DE DIREITOS HUMANOS, 2020).

Assim, percebe-se a necessidade de maior reflexão sobre a proteção de dados pessoais sensíveis, principalmente no campo médico, durante a pandemia, devendo-se analisar essa questão sob o viés dos direitos da personalidade e dos referenciais bioéticos. 


\section{OS DADOS CLÍNICOS SOB O VIÉS DA TEORIA GERAL DOS DIREITOS DA PERSONALIDADE}

Os direitos da personalidade revelam-se essenciais na atualidade, porquanto trazem uma necessária e esperada proteção no âmbito civil para a essencialidade humana.

Inspirado principalmente na lei civil italiana, o capítulo próprio sobre mencionados direitos, previsto com a edição do Código Civil de 2002, trouxe uma mudança paradigmática na proteção a pessoa humana em sua integralidade, tendo a dignidade como diretriz.

De fato, o fundamento da dignidade da pessoa humana revela-se imprescindível para nortear a proteção aos direitos vinculados a personalidade, consistindo em verdadeira "diretriz".

Os direitos da personalidade são descritos pela doutrina como:

A qualidade intrínseca e distintiva reconhecida em cada ser humano que o faz merecedor do mesmo respeito e consideração por parte do Estado e da comunidade, implicando, neste sentido, um complexo de direitos e deveres fundamentais que assegurem a pessoa tanto contra todo e qualquer ato de cunho degradante e desumano, como venham a lhe garantir as condições existenciais mínimas para uma vida saudável, além de propiciar e promover sua participação ativa e co-responsável nos destinos da própria existência e da vida em comunhão com os demais seres humanos (SARLET, 2001, p. 59-60).

Percebe-se, assim, a imprescindibilidade de concretização do fundamento da dignidade da pessoa humana, em todas as suas dimensões, como forma de viabilizar as especificas tutelas aos mais diversos direitos da personalidade. Conforme bem afirma Alessandra Cristina Furlan et al (2007, p. 78):

Como princípio fundamental, a dignidade da pessoa humana constitui uma norma jurídico-positiva dotada de eficácia e apresenta proeminência axiológiconormativa sobre todos os demais princípios e sistema jurídico infraconstitucional. Nada obstante, a mera previsão constitucional não faz com que o princípio seja respeitado e efetivado. Essa efetivação se dá pela concretização das condições que tornem possível a plenitude constitucional consagrada. Por essa razão, a Constituição Federal de 1988 elaborou um amplo, flexível e aberto sistema de direitos e garantias fundamentais que busca concretizar na prática esse princípio. Ainda com relação à elevação da dignidade da pessoa humana como fundamento da República Federativa do Brasil é possível afirmar: como princípio, confere unidade axiológico-normativa ao sistema constitucional, harmonizando os diversos dispositivos; serve de parâmetro para a aplicação, a interpretação e a integração de todo o ordenamento jurídico; como cláusula aberta respalda o surgimento de novos direitos; consiste em limite para as modificações constitucionais e funciona como parâmetro de controle da legitimidade substancial do poder estatal.

De acordo com Adriano de Cupis, todos os direitos, na medida em que destinados a dar conteúdo a personalidade, poderiam chamar-se "direitos da personalidade". No entanto, na 
linguagem jurídica corrente esta designação e reservada aqueles direitos subjetivos cuja função, relativamente a personalidade, e especial, constituindo o "minimum" necessário e imprescindível ao seu conteúdo:

Por outras palavras, existem certos direitos sem os quais a personalidade restaria uma susceptibilidade completamente irreal, privada de todo o valor concreto: direitos sem os quais todos os outros direitos subjectivos perderiam todo o interesse para o individuo - o que equivale dizer que, se eles não existissem, a pessoa não existiria como tal. São esses os chamados "direitos essenciais", com os quais se identificam precisamente os direitos da personalidade (DE CUPIS, 1961, p. 17).

Os direitos de personalidade devem ser compreendidos como: a) os próprios da pessoa em si (ou originários), existentes por sua natureza, como ente humano, com o nascimento; b) e os referentes às suas projeções para o mundo exterior (a pessoa como ente moral e social, ou seja, em seu relacionamento com a sociedade) (BITTAR, 2000).

A palavra pessoa vem do latim "persona", de "personare", que significa ressoar (LIMA, 1984, p. 140). "Persona" constituía-se na máscara utilizada pelos antigos atores romanos e cuja boca, munida de lâminas metálicas, era disposta de modo a aumentar a voz, para que melhor ressoasse nos vastos anfiteatros em que se apresentavam.

Posteriormente, passou-se a utilizar o termo pessoa em seu sentido técnico, ou seja, o homem dotado de capacidade jurídica. Os direitos de personalidade são uma construção teórica recente. Têm como objeto o bem jurídico da personalidade, entendida como a titularidade de direitos e deveres que se consideram ínsitos a toda a pessoa em razão do que estas se tornam sujeitos das relações jurídicas.

A Constituição Federal de 1988 conferiu à pessoa uma série de direitos relacionados à sua personalidade. A legislação infraconstitucional, por sua vez, passou a acompanhar e conferir maior importância à proteção de mencionados direitos. De fato, os direitos de personalidade não podem ser considerados como numerus clausus, o que limitaria sua proteção.

Com efeito, restringir a proteção dos direitos de personalidade a um rol fechado, estanque, seria reduzir as diversas formas protetivas da pessoa. Elimar Szaniawski (1993) compreende não ser adequado essa tipificação, devendo realizar uma análise dos limites dos direitos da personalidade no caso concreto.

Diante disso, enumerar os direitos de personalidade trás nenhuma satisfação aos anseios do homem, uma vez que este deseja a tutela estatal para solucionar eventuais violações à sua dignidade, como um todo.

O Estado precisa assumir a responsabilidade de impedir que, no exercício do controle de suas atividades, ninguém esteja abusando dos direitos inatos à pessoa. Portanto, leis eficazes devem fornecer proteção contra esse mau uso.

Ademais, deve-se destacar que a evolução dos direitos de personalidade repercute em vá- 
rios ramos do direito, especialmente no direito civil, uma vez que regulamenta os casos e hipóteses de reparação de danos decorrentes da violação dos mesmos.

O hoje denominado "compartilhamento máximo de dados" parece ser a tônica na contextualização pandémica, mas precisa ser limitado.

Tal limitação se torna possível por meio da teoria geral dos direitos da personalidade, que deve ser resgatada e implementada celeremente. Isto porque frequentes situações de violação têm sido observadas há tempos, mas especificamente em razão da pandemia da Covid-19 revelaram-se latentes.

Em relação a utilização e exposição de dados clínicos, a contribuição da teoria geral dos direitos da personalidade se da especificamente no direito a privacidade. Ainda que já previsto constitucionalmente, a lei civil brasileira sedimentou tal proteção, conferindo eficácia e facilitando diversos mecanismos de controle judicial visando a sua tutela.

A Constituição Federal no art. 5. ${ }^{\circ}$, inciso X, assegura a tutela da privacidade: são invioláveis a intimidade, a vida privada, a honra e a imagem das pessoas, assegurado o direito a indenização pelo dano material ou moral decorrente de sua violação.

Já o artigo 21 do Código Civil dispõe que "A vida privada da pessoa natural é inviolável, e o juiz, a requerimento do interessado, adotará as providências necessárias para impedir ou fazer cessar ato contrário a esta norma”.

O direito a privacidade pode ser entendido como a proteção de toda manifestação de cunho particular. Consiste na faculdade que tem cada indivíduo de obstar a intromissão de estranhos na sua vida privada e familiar, assim como de impedir-lhes acesso a informações sobre a privacidade de cada um e também impedir que sejam divulgadas informações sobre esta área da manifestação existencial do ser humano (BASTOS, 1997).

Deve-se destacar a diferença entre privacidade e intimidade, apesar de ambas serem protegidas. A intimidade corresponde à esfera secreta da vida pessoa, envolvendo a inviolabilidade do domicílio, o sigilo da correspondência e o segredo profissional. Enquanto que a privacidade detém um conceito mais amplo, envolvendo todas as manifestações de esfera íntima, privada e da personalidade da pessoa (SILVA, 2009, p. 206)

Não se devem admitir interferências injustificadas nos dados sensíveis, especificamente informações clínicas, por se tratarem de extensão da privacidade da pessoa. Conforme Gilberto Haddad Jabur (2000) afirma:

O direito a privacidade, tão importante e presente em nosso dia a dia, nas mais comezinhas manifestações de existência, deve, desse modo, renovar a preocupação sociojurídica em conter os abusos espraiados contra os bens personalíssimos, dos quais dependem, sem rebuco de duvida, antes da satisfação, a própria razão de viver. A privacidade e o refugio impenetrável pela coletividade, devendo, portanto, ser respeitada.[...]

Nem mesmo o manto do sempre invocado interesse publico ou social - conceito indeterminado e vago, alem de impreciso quanto ao seu alcance - e termômetro idôneo para legitimar a invasão irrestrita da esfera privada de quem quer que seja. 
Assim, a teoria geral dos direitos da personalidade, mormente no que se refere a proteção da vida privada, revela-se como diretriz salutar na proteção aos dados clínicos durante a pandemia.

O próximo tópico versara sobre os balizadores bioéticos na proteção a privacidade dos dados clínicos, porquanto se entende que a junção do critério apresentado neste item com a elevação dos referenciais bioéticos como diretrizes interpretativas pode servir sobremaneira a proteção dos dados clínicos no contexto da pandemia.

\section{O PAPEL DA BIOÉTICA COMO BALIZADORA DOS CONFLITOS}

Para auxiliar na discussão sobre a proteção e limites ao direito à privacidade sobre os dados clínicos sensíveis, deve-se observar os referenciais bioéticos como norteadores da discussão.

Primeiramente deve-se entender o que é Biodireito e quais são os referenciais ou princípios bioéticos. A Bioética é "um estudo interdisciplinar, ligado à ética, que investiga, na área das Ciências da Vida e da Saúde, a totalidade das condições necessárias a uma administração responsável da vida humana em geral e da pessoa humana em particular" (SAUWEN; HRYNIEWICZ, 2000, p. 31).

Então, percebe-se que a Bioética tem como intuito apresentar uma reflexão mais filosófica e ética a respeito dos avanços biotecnológicos, discutindo seus limites e sua aplicação sobre o ser humano.

A respeito da atuação da Bioética, Daisy Gogliano (2000, p. 116) pontua:

A Bioética vem florescendo como uma "nova ciência", ocupando-se de todas as questões que envolvem os atos de disposição do próprio corpo, tais como a experimentação humana para fins científicos e terapêuticos, a doação de órgãos e tecidos humanos, a inseminação in vitro, a biotecnologia aplicada a Medicina, o aborto, a eutanásia, a recusa de tratamento médico por parte do paciente, "o direito de morrer com dignidade", e todas as demais questões que envolvem conteúdos valorativos e busca de padrões morais tanto individuais como coletivos.

No atual cenário de pandemia, a Bioética adquire um novo destaque como ferramenta capaz de auxiliar na discussão da utilização das tecnologias e no tratamento de dados clínicos para pesquisa e acesso à informação dos cidadãos. Os dados clínicos são essenciais para pesquisa e tratamento da doença, contudo, a esfera íntima deve ser respeitada.

Nesse campo, os princípios ou referenciais bioéticos auxiliam como mecanismos de interpretação da utilização dos dados. A bioética contém quatro princípios: autonomia, beneficência, não maleficência e justiça. Com exceção do princípio da não maleficência ${ }^{2}$, os demais princípios têm sua origem no Belmont Report no final da década de 1970 (DINIZ, 2008, p. 38). Deve-se conceituar os quatros princípios bioéticos e compreender como podem auxiliar na proteção dos dados $\overline{2} \mathrm{O}$ princípio da não maleficência surgiu como um desdobramento do princípio da beneficência. 
sensíveis.

Primeiramente, o princípio da autonomia relaciona-se com a capacidade da pessoa decidir sobre a sua saúde e seu corpo. Isso significa que "respeitar um agente autônomo é, no mínimo, reconhecer o direito dessa pessoa de ter suas opiniões, fazer suas escolhas e agir com base em valores e crenças pessoais" (BEAUCHAMP; CHILDRESS, 2013, p. 142).

No campo da pandemia, principalmente na área de pesquisas clínicas, deve ser sempre preservado a consentimento do paciente/voluntário de forma livre, especialmente a respeito de seus dados. Os dados clínicos correspondem a uma expansão da esfera pessoal do indivíduo, digna de preservação.

O segundo princípio é o da beneficência, entendido como fazer o bem para o paciente, não causando nenhum dano a sua saúde. Assim, tem, como um dos seus resultados o dever de manter o sigilo médico (SANTOS, 1998, p. 43). Como desdobramento desse princípio, há o princípio da não maleficência que prevê que o profissional da saúde não deve gerar dano intencional ao paciente (SANTOS, 1998, p. 43).

No atual cenário mundial da pandemia, os princípios da beneficência e da não maleficência mostram-se ainda mais fundamentais do que nunca. Os tratamentos utilizados, apesar de não existir um tratamento certo, devem sempre ser ponderados no sentido de causar o menor dano possível ao paciente. Ademais, no tocante as informações, não se deve esquecer do direito ao sigilo que as informações médicas detêm. Logo, os dados sensíveis, além de conter previsão legal de proteção, também são resguardados por esse princípio.

Outro princípio é o da justiça que prevê uma "distribuição justa, equitativa e universal dos benefícios dos serviços de saúde” (SANTOS, 1998, p. 43). A distribuição e acesso de tratamento deve ser igualitária (SANTOS, 1998, p. 39).

Sobre a COVID-19 é importante pontuar que com base nesse princípio, havendo uma vacina ou descoberta de um tratamento eficaz, deve ocorrer a sua disponibilização para o mundo, uma vez que a distribuição deve ser "justa, equitativa e universal".

Percebe-se assim, a imprescindibidade de se alçar os princípios ou referenciais bioéticos a um patamar adequado a sua efetiva implementação hermenêutica no tratamento de dados sensíveis.

No campo médico brasileiro, o Código de Ética Médica (CEM) (BRASIL, 2018) concretiza diversos ideais dos referenciais bioéticos como a proibição do profissional causar dano ao paciente (cap. III, art. $1^{\circ}$ ) e a proibição de não observância a autonomia do paciente (Cap. IV, art. 24).

No tocante as informações, o Código de Ética Médica (BRASIL, 2018) veda o profissional de saúde revelar informações confidenciais dos pacientes (art. 76), devendo sempre guardar o sigilo sobre as informações adquiridas por meio de sua atividade (cap. I, XI). Isso se fundamenta em vários referenciais como autonomia do paciente e beneficência.

Nota-se que o CEM busca concretizar os referencias bioéticos por meio de normativas, contudo, devido a pandemia, não basta apenas a previsão de tais dispositivos, mas sua aplicação de forma efetiva. Os referenciais devem ser utilizados efetivamente nos casos, principalmente nas 
situações novas e emergenciais que surgem na atual realidade, a fim de obter respostas adequadas aos parâmetros éticos desejados pela sociedade.

\section{CONCLUSÃO}

A pandemia trouxe a tona uma série de desafios jurídicos, que devem ser enfrentados a luz do sistema normativo e ético vigente. Nesse âmbito, torna-se necessário o estabelecimento de balizas norteadoras da tutela do ser humano. A possibilidade de acesso à informações clínicas de pacientes em razão de procedimentos remotos e/ou de controle estatal demanda uma discussão jurídica que envolve a necessidade de criação de diretrizes capazes de um tutela eficaz.

Assim, tendo como ponto de partida a dignidade da pessoa humana, a teoria geral dos direitos da personalidade - especificamente a tutela da privacidade - e apontada como uma das alternativas balizadoras da proteção da pessoa, não se justificando acesso desnecessário, tampouco divulgações daquelas informações, exceto em situações limite.

Os referenciais bioéticos da autonomia, justiça, beneficência e não maleficência são aqui apontados como mais uma alternativa hábil a direcionar a proteção de dados - especificamente clínicos - , objeto do presente estudo, porquanto a Bioética e o Biodireito tem se revelado profícuas áreas nas tratativas dos desafios pandêmicos e pôs pandémicos.

Busca-se enfrentar situação temerária, entendida por alguns como "imprevisível", com base em normas jurídicas e morais que possam dar conta de manter o Estado Democrático de Direito e o ideal equitativo.

\section{REFERÊNCIAS}

BASTOS, Celso R. Hermenêutica e interpretação constitucional. Instituto Brasileiro de Direito Constitucional: São Paulo, 1997.

BEAUCHAMP, Tom L.; CHILDRESS, James F. Princípio de ética biomédica. Tradução: Luciana Pudenzi. 3. ed. São Paulo: Loyola, 2013.

BITTAR, Carlos Alberto. Os direitos da personalidade. 4. ed. Rio de Janeiro: Forense Universitária, 2000.

BRASIL. Imprensa Oficial. Resolução n ${ }^{\circ} 2.217$, de 27 de setembro de 2018. Aprova o Código de Ética Médica. Diário da Oficial da União: seção 1, Brasília, DF, ano 221, p. 179, 2018. Disponível em: https://www.in.gov.br/materia/-/asset_publisher/Kujrw0TZC2Mb/content/id/48226289/ do1-2018-11-01-resolucao-n-2-217-de-27-de-setembro-de-2018-48226042. Acesso em: 13 jul. 2020. 
BRASIL. Lei n. 13.709, de 14 de agosto de 2018. Lei Geral de Proteção de Dados Pessoais (LGPD). Brasília: Presidência da Repúbllica, 2018. Disponível em: http://www.planalto.gov.br/ccivil_03/_ato20152018/2018/lei/113709.htm. Acesso: 13 jul 2020.

CARVALHAL, Gustavo Franco et al. Recomendações para a proteção da privacidade do paciente. Revista Bioética, Brasília, v. 25, n. 1, p. 39-43, abr. 2017. Disponível em: http://www.scielo.br/scielo.php?script=sci_arttext\&pid=S1983-80422017000100039\&lng=pt\&nrm=iso. acessos em: 13 jul. 2020.

COMISSÃO INTERAMERICANA DE DIREITOS HUMANOS. Resolução 1/2020: Pandemia e direitos humansos nas américas. Adotada pela CICH em 10 de abril de 2020, p. 1-22. Washington: OEA, 2020. Disponível em: https://www.oas.org/pt/cidh/decisiones/pdf/Resolucao-1-20-pt.pdf. Acesso em: 13 jul 2020 .

COMITÊ NACIONAL DE BIOÉTICA DA REPÚBLICA DE SÃO MARINO. Answer to the requested urgent opinion on the ethical issues regarding to the use of invasive assisted ventilation in patients all age with serious disabilities in relation to covid-19 pandemic. Republica of San Marino, National Bioethics Committee, approved on march 16, 2020. Tradução Luisa Borgia. p. 1-5.

CORRÊA, Adriana Espíndola; LUZ, Pedro Henrique Machado da. A exceção na proteção de dados pessoais durante a Covid-19 - parte 1. Direito Civil Atual. Consultor Jurídico. Publicado em 22 de maio de 2020. Disponível em: https://www.conjur.com.br/2020-mai-22/direito-civil-atual-excecao-protecao-dados-pessoais-durante-covid-19. Acesso em: 13 jul. 2020.

DADALTO, Luciana. Direito, bioética e pandemia de Covid-19. Coluna Direito e Bioética. Migalhas. Publicado em 1 de julho de 2020. Disponível em: https://m.migalhas.com.br/coluna/ direito-e-bioetica/328023/direito-bioetica-e-pandemia-da-covid-19?u=cf2543a5_2e2\&utm_source=informativo\&utm_medium=1083\&utm_campaign=1083. Acesso em: 13 jul 2020.

DE CUPIS, Adriano. Os direitos da personalidade. Lisboa: Morais Editora, 1961.

DINIZ, Maria Helena. O estado atual do biodireito. 5. ed. São Paulo: Saraiva, 2008.

\section{EUROPEAN MEDICINES AGENCY. Guidance on the Management of Clinical Trials}

during the COVI-19 (Coronavirus) pandemic. Version 2 (27/02/2020). Disponível em: https:// ec.europa.eu/health/sites/health/files/files/eudralex/vol-10/guidanceclinicaltrials_covid19_en.pdf. Acesso em: 1 maio 2020.

FURLAN, Alessandra Cristina, et al. Dignidade da pessoa humana. UNOPAR CIENTÍFICA. Ciências Jurídicas e Empresariais, Londrina, v. 8, n. 1, p. 73-80, mar. 2007.

GEDIEL, José Antônio Peres; CORRÊA, Adriana Espíndola. Proteção jurídica de dados pessoais: a intimidade sitiada entre o estado e o mercado. Revista da Faculdade de Direito UFPR, Curitiba, n. 47, p. 141-153, 2008.

GOGLIANO, Daisy. Autonomia, bioética e direitos da personalidade. Revista de Direito Sanitário, São Paulo, v. 1, n. 1, p. 107-127, nov. 2000.

HARARI, Yuval Noah. The world after coronavírus. Financial Times. Publicado em 20 de março de 2020. Disponível em: https://www.ft.com/content/19d90308-6858-11ea-a3c9-1fe6fedc- 
ca75. Acesso em: 27 abr 2020.

HARVEY, David. Política anticapitalista en tempos de COVID-19. In: Sopa de Wuhan. Editoria ASPO (Aislamiento Social Preventivo y Obligatorio). 2020.

JABUR, Gilberto Haddad. Liberdade de pensamento e direito a vida privada. São Paulo: Editora Revista dos Tribunais, 2000.

JACOMINI, Grasiani. Lista com nomes de pacientes com Covid-19 vaza no norte do PR. CBN Curitiba. Disponível em: https://cbncuritiba.com/lista-com-nomes-pacientes-covid-19-vaza-norte-pr/. Acesso em: 14 jul 2020.

LIMA, João Franzen. Curso de direito civil brasileiro. Rio de Janeiro: Forense, 1984.

ORGANIZAÇÃO MUNDIAL DA SAÚDE. Cronologia do vírus na OMS. Disponível em: https://www.who.int/es/news-room/detail/08-04-2020-who-timeline---covid-19. Acesso em: 13 jul 2020.

SANTOS, Maria Celeste Cordeiro Leite. Equilíbrio de um pêndulo: bioética e a lei: implicações médico-legais. São Paulo: Ícone, 1998.

SARLET, Ingo. Dignidade da pessoa humana e direitos fundamentais na Constituição Federal de 1988. 2 ed. Porto Alegre: Livraria do Advogado, 2001.

SARLET, Ingo Wolfgang; KEINERT, Tania Margarete Mezzomo. O direito fundamental à privacidade e as informações em saúde: alguns desafios. In: KEINERT, Tânia Margarete Mezzomo et al (org.). Proteção à privacidade e acesso às informações em saúde: tecnologias, direitos e ética. São Paulo: Instituto de Saúde, 2015, p. 113-146.

SAUWEN, Regina Fiuza; HRYNIEWICZ, Severo. O Direito "in vitro"- da bioética ao biodireito: temas polêmicos, legislação atualizada, projetos de lei. 2. ed. Rio de Janeiro: Lumen Juris, 2000 .

SILVA, José Afonso da. Curso de Direito Constitucional Positivo. 32 ed. São Paulo: Malheiros, 2009.

SZANIAWSKI, Elimar. Direitos de Personalidade e sua Tutela. São Paulo: Revista dos Tribunais, 1993.

TAVARES, Bruno. Jornal pede à Justiça de SP que hospital e laboratório comprovem que exames de Covid-19 eram de Bolsonaro. G1: São Paulo, 19 maio 2020. Disponível em: https://g1.globo. $\mathrm{com} / \mathrm{sp} /$ sao-paulo/noticia/2020/05/19/jornal-pede-a-justica-em-sp-que-hospital-e-laboratorio-comprovem-que-exames-de-covid-19-eram-de-bolsonaro.ghtml. Acesso em: 13 jul 2020.

Como citar: PAVÃO, Juliana Carvalho; ESPOLADOR, Rita de Cássia Resquetti Tarifa. A proteção de dados clínicos durante a pandemia da covid-19: comentários à luz dos direitos da personalidade e dos referenciais bioéticos. Scientia luris, Londrina, v. 25, n. 3, p. 125-140, nov. 2021. DOI: 
10.5433/21788189.2021v25n3p125. ISSN: 2178-8189.

Recebido em 2021-02-27

Aprovado em 2021-10-25 